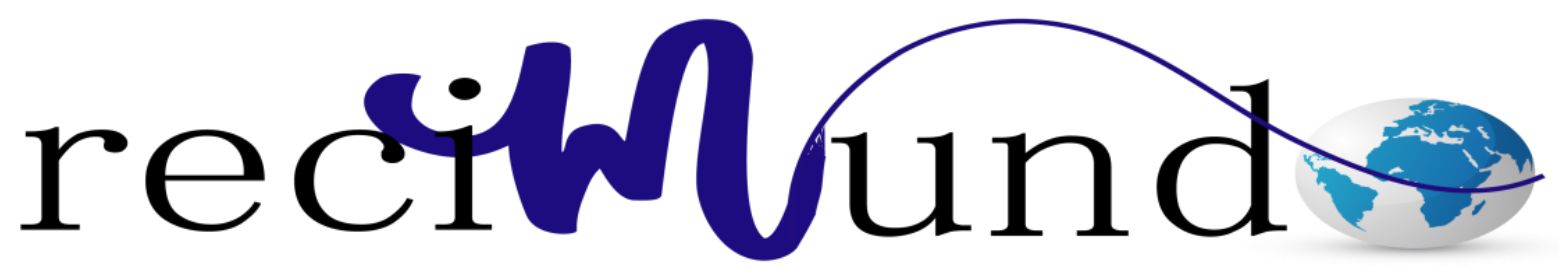

Revista Científica Mundo de la Investigación y el Conocimiento

Bertha Elizabeth Benavides Yánez ${ }^{\text {a }}$, Mery Adriana Franco Carrasco b; Roberto Jairo Tuesca Armijos ${ }^{c}$; Marcelo Kevin Taiano Espinoza d

Enfermedades de transmisión sexual en niños y adolescentes, contagio por el virus del papiloma humano

Sexually transmitted diseases in children and adolescents, contagion by the human

$$
\text { papillomavirus }
$$

Revista Científica Mundo de la Investigación y el Conocimiento. Vol. 2 núm.3, julio, ISSN: 2588-073X, 2018, pp. 410-421

DOI: 10.26820/recimundo/2.(3).julio.2018.410-421

Editorial Saberes del Conocimiento

Recibido: 05/04/2018

Aceptado: 03/06/2018

Publicado: 30/07/2018

Correspondencia: elizabethbenavidesy@hotmail.com
a. Médico; elizabethbenavidesy@hotmail.com
b. Magister en Seguridad Higiene Industrial y Salud Ocupacional; Medico; meryjean_21@ hotmail.com
c. Médico; mustangstrife@gmail.com
d. Médico; el_gato_marcello@hotmail.com 


\section{Enfermedades de transmisión sexual en niños y adolescentes, contagio por el virus del papiloma humano \\ Vol. 2, núm. 3., (2018)}

Bertha Elizabeth Benavides Yánez; Mery Adriana Franco Carrasco; Roberto Jairo Tuesca Armijos; Marcelo Kevin Taiano Espinoza

\section{RESUMEN}

El aumento actual de las enfermedades de transmisión sexual específicamente el virus del papiloma humano entre niños y adolescentes y las graves consecuencias que pueden seguir a la infección deben hacer que la prevención de este tipo de infecciones en este grupo de edad sea una prioridad. La identificación de una enfermedad de transmisión sexual en un niño más allá del período neonatal tiene implicaciones médicas y legales. La gonorrea y la sífilis se transmiten casi exclusivamente por vía sexual y son marcadores útiles de abuso sexual en los niños. Sin embargo, las excepciones ocurren; por ejemplo, la infección rectal y genital con Chlamydia trachomatis en niños pequeños puede deberse a una infección perinatal persistente, que puede persistir durante hasta 3 años. La infección causada por el virus del papiloma humano (condiloma acuminado) presenta un problema similar, ya que el período de latencia después de la adquisición perinatal puede ser de 2 años o más. Otras enfermedades de transmisión sexual, como la vaginosis bacteriana, pueden adquirirse de forma no sexual y se han identificado tanto en niños maltratados como en niños no abusados. Cuando la única evidencia de abuso sexual es el aislamiento de un organismo o la detección de anticuerpos, los hallazgos deben ser cuidadosamente confirmados.

Palabras claves: Enfermedad de transmisión sexual, Papiloma, Niños. 


\title{
Enfermedades de transmisión sexual en niños y adolescentes, contagio por el virus del papiloma humano
}

Vol. 2, núm. 3., (2018)

Bertha Elizabeth Benavides Yánez; Mery Adriana Franco Carrasco; Roberto Jairo Tuesca Armijos; Marcelo Kevin Taiano Espinoza

\begin{abstract}
The current increase in sexually transmitted diseases specifically the human papillomavirus among children and adolescents and the serious consequences that can follow infection should make the prevention of this type of infections in this age group a priority. The identification of a sexually transmitted disease in a child beyond the neonatal period has medical and legal implications. Gonorrhea and syphilis are almost exclusively transmitted sexually and are useful markers of sexual abuse in children. However, exceptions do occur; For example, rectal and genital infection with Chlamydia trachomatis in young children may be due to persistent perinatal infection, which may persist for up to 3 years. Infection caused by the human papillomavirus (condyloma acuminata) presents a similar problem, since the latency period after perinatal acquisition can be 2 years or more. Other sexually transmitted diseases, such as bacterial vaginosis, can be acquired non-sexually and have been identified in both abused and non-abused children. When the only evidence of sexual abuse is the isolation of an organism or the detection of antibodies, the findings should be carefully confirmed.
\end{abstract}

Keywords: Sexually transmitted disease, Papilloma, Children 


\section{Enfermedades de transmisión sexual en niños y adolescentes, contagio por el virus del papiloma humano \\ Vol. 2, núm. 3., (2018)}

Bertha Elizabeth Benavides Yánez; Mery Adriana Franco Carrasco; Roberto Jairo Tuesca Armijos; Marcelo Kevin Taiano Espinoza

\section{Introducción.}

El reconocimiento de que las verrugas ano genitales en adultos son predominantemente una enfermedad de transmisión sexual ha llegado solo en los últimos 40 años. Durante todo el siglo pasado, la enfermedad fue atribuida a la falta de higiene o irritación de gonococo y otras causales. Su etiología viral fue descubierta temprano en el presente siglo, pero se pensaba que solo había un virus del papiloma humano (VPH), que causaba todo tipo de verrugas, y ese contacto sexual fue solo una de las muchas formas en que este virus podría alcanzar el epitelio ano genital. El concepto moderno de infección por VPH tiene desarrollado a partir de una investigación clínica y virológica. Las verrugas ano genitales en adultos son ahora consideradas como una enfermedad de transmisión sexual; la epidemiología de las infecciones subclínicas por VPH es menos establecido, pero es probable que estos también son transmitidos sexualmente.

La virología molecular ha demostrado que hay al menos 60 Genotipos de VPH. VPH 1-4 son predominantemente asociado con verrugas cutáneas de áreas no genitales, VPH 6 y 11 con condiloma acuminato, verrugas papilares y ano genitales y VPH 16, 18 y más raramente VPH 31, 35, 39 y 41-45 con displasia del cuello uterino, vulva, pene y ano. (Piconni, 2013)

Se mencionaron las verrugas genitales en niños en la literatura temprana de una manera muy superficial, el primero informe del caso, que describió una niña de 3 años con gonorrea y múltiples condilomas vulvares, no aparecieron hasta 1940 y entre entonces y 1980 solo se informaron de 18 nuevos otros casos. (Stumpf, 1980) 


\section{Enfermedades de transmisión sexual en niños y adolescentes, contagio por el virus del papiloma humano}

Vol. 2, núm. 3., (2018)

Bertha Elizabeth Benavides Yánez; Mery Adriana Franco Carrasco; Roberto Jairo Tuesca Armijos; Marcelo Kevin Taiano Espinoza

En los últimos años ha habido un aumento marcado en el número de casos publicados; ya que la enfermedad no es difícil de diagnosticar, esto puede reflejar un verdadero aumento en la incidencia, en paralelo con la epidemia actual de verrugas ano genitales en adultos.

Sugerencias de que el condiloma acuminado en los niños pueden ser un signo de abuso sexual comenzó aparecer en la década de 1970, (Ñíguez, García, Pérez, Guillén, \& Mari, 1996) y su lugar en la historia natural de la enfermedad ha sido discutido en varias ocasiones desde entonces.

\section{Metodología}

Esta investigación está enfocada en el estudio de las enfermedades de transmisión sexual en niños y adolescentes específicamente con referencia a la infección del virus del papiloma humano.

La revisión se ha centrado en textos, documentos y artículos científicos publicados disponibles en la web, considerando que aquella herencia de la globalización nos permite acceder a mayor y mejor información a través de las herramientas tecnológicas. El motor de búsqueda ha sido herramientas académicas de la web que direccionan específicamente a archivos con validez y reconocimiento científico, descartando toda información no confirmada o sin las respectivas referencias bibliográficas. 


\section{Enfermedades de transmisión sexual en niños y adolescentes, contagio por el virus del papiloma humano \\ Vol. 2, núm. 3., (2018)}

Bertha Elizabeth Benavides Yánez; Mery Adriana Franco Carrasco; Roberto Jairo Tuesca Armijos; Marcelo Kevin Taiano Espinoza

\section{Resultados}

Parece que hay varias formas en que el VPH puede alcanzar el área ano genital del niño y causar verrugas:

- de la madre antes del nacimiento

- de la madre durante el parto

- a través de un contacto cercano pero no sexual con un miembro del círculo familiar

- a través de uno o más encuentros sexuales

- a través de la transferencia de VPH de las verrugas por el propio niño desde la mano o las manos de otros niños o adultos. (Mataix, Betlloch, Pasto, Bañuls, \& Martínez, 2008)

Se sabe muy poco sobre la epidemiología subclínica o latente del VPH ano genital en niños.

(Marquina, 2013) informaron la aparición de condiloma acuminado congénito en un prematuro infantil; presumiblemente la infección fue por un infección ascendente del tracto genitales de la madre o, concebiblemente, a través de la viremia maternal. (Zacharisen, \& Conley, 2006) informó el caso de un niño cuya madre tenía verrugas genitales en el momento del nacimiento; a la edad de seis meses desarrolló verrugas del pene, y a la edad de 18 meses papilomas laríngeos. Estudiaron 73 niños con verrugas ano genital. Siete de estos tenía verrugas al nacer, de acuerdo con sus padres; uno de estos, cuya madre era conocida por tener verrugas genitales, el nacimiento fue por cesárea. 


\section{Enfermedades de transmisión sexual en niños y adolescentes, contagio por el virus del papiloma humano}

Vol. 2, núm. 3., (2018)

Bertha Elizabeth Benavides Yánez; Mery Adriana Franco Carrasco; Roberto Jairo Tuesca Armijos; Marcelo Kevin Taiano Espinoza

Estos y otros casos indican que Las verrugas ano genitales en niños pueden deberse a infección de sus madres durante, o incluso antes del nacimiento. Esta idea es apoyada por un informe que el análisis por hibridación dot-blot de 70 prepucios de infantes sometidos a la rutina de circuncisión demostró que dos contenían secuencias de HPV 16 y una de HPV 6; si la infección ocurrió durante el parto o en el útero no se pudo determinar. (Picconi, 2013)

Los papilomas laríngeos juveniles también están relacionados con la maternidad, verrugas genitales no se presentan antes de los tres o cuatro meses de edad y casi la mitad no son diagnosticado antes de la edad de dos años, lo que sugiere un largo período de incubación para estas infecciones. El incierto período de incubación de la infección por VPH se suma a la dificultad de establecer una causa para las verrugas ano genitales en niños. La evidencia de que los niños pueden contraer verrugas ano genitales a través de contacto no sexual cercano con un miembro de la familia es anecdótica. Un niño investigado por una serie de médicos en los años 90 puede haber sido infectado por el baño con un pariente femenino que tenía verrugas genitales. (Mouesca, Indart, Stabilito, 2012) Tenían un caso similar. Estos autores también vieron a un niño con verrugas genitales que tenía estenosis anal que estaba siendo dilatado por la madre, que también informaron tener verrugas.

Los autores sugieren que en algunos casos infección con HPV en niños puede ocurrir temprano en la vida, muy probablemente por transmisión asexual o durante el nacimiento.

Durante la última década se ha detectado, particularmente por los casos dados en los Estados Unidos, que la mayoría de casos de verrugas ano genitales en los niños se deben a abuso sexual". En un estudio reciente (5. Robinson,\& Watkeys , 1999) encontraron que 10 de 11 


\section{Enfermedades de transmisión sexual en niños y adolescentes, contagio por el virus del papiloma humano \\ Vol. 2, núm. 3., (2018)}

Bertha Elizabeth Benavides Yánez; Mery Adriana Franco Carrasco; Roberto Jairo Tuesca Armijos; Marcelo Kevin Taiano Espinoza

chicas con verrugas genitales tenían un aspecto histórico y / o con evidencia física de abuso sexual; tres de las chicas estaban infectadas por Neisseria gonorrhoeae y uno por Trichomonas vaginalis, y los autores sugieren que todas, o casi todas, las verrugas genitales en los niños son transmitidos sexualmente. Esta opinión no es unánime.

Igualmente revisaron 37 casos de verrugas ano genitales en ambos sexos, de las cuales solo se pensó que nueve se debían al abuso, es cierto, en diez casos no hubo información sobre el presunto medio de infección. Finalmente, en un estudio reciente 73 niños con verrugas ano genitales fueron cuidadosamente evaluados por abuso sexual, pero en 66 de ellos no había evidencia de que tal abuso hubiera ocurrió.

En algunos niños con verrugas ano genitales más de un factor causal potencial puede estar presente; el abuso sexual puede haber ocurrido en algunos casos donde la transmisión vertical podría haber sido auto inoculación de VPH o inoculación de otros niños durante el juego, ha sido sugerido como una posible causa de algunos casos de verrugas ano genitales.

La mayoría de las verrugas ano genitales en niños afecta las áreas vulvares y perianales; las verrugas peneanas en los niños son muy inusuales, aunque han sido descritas. Puede haber ocasionalmente lesiones verrugosas asociadas en la piel del cuerpo o en la boca. Como en los adultos, tres tipos de lesión asociada al VPH se puede identificar, condilomatoso, papilar y plano (subclínico).

Los condilomas acuminados clásicos son suaves y carnosos y tumores vasculares de tamaño ampliamente variable y forma; pueden unirse para formar grandes masas. Con aumento, 


\section{Enfermedades de transmisión sexual en niños y adolescentes, contagio por el virus del papiloma humano}

Vol. 2, núm. 3., (2018)

Bertha Elizabeth Benavides Yánez; Mery Adriana Franco Carrasco; Roberto Jairo Tuesca Armijos; Marcelo Kevin Taiano Espinoza

varios patrones capilares han sido identificados: "horquilla, sacacorchos, horcas o abanicos ".

(Picconi, 2013) 'En las niñas estos condilomas usualmente afectan las áreas húmedas como el introito vaginal, uretral, perineal y áreas perianales, pero pueden afectar cualquier sitio ano genital. Condilomas vulvares y uretrales puede volverse muy grandes, nn niños, los condilomas más a menudo afectan el área perianal y áreas perigenitales. Se ha sugerido que la presencia de lesiones que son perianales, además de estar en las nalgas o los pliegues de las nalgas, fortalecen la posibilidad de abuso sexual. (Goldman \& Clarke, 1980)

En los adultos, los condilomas perianales a menudo afectan el canal anal también; si esto también ocurre en los niños no están claros en este momento. Las verrugas papilares (sésiles), son las más comunes en partes completamente queratinizadas del epitelio ano genital. Por lo general son múltiples y abultadas, de 1-3 mm de diámetro, y con un superficie lisa. Las verrugas planas (verruga subclínica infección por virus) se pueden identificar con aumento después de la aplicación de 5\% de ácido acético. Pueden ocurrir solas o en asociación con otros tipos de verruga, son de tamaño muy variable y forma, y son característicamente "blanco brillante" en color. Información sobre la ocurrencia de estas lesiones en niños es escasa, pero han sido descritos. En adultos colposcópicos, anormalidades citológicas e histológicas del cuello uterino es común en mujeres con verrugas vulvares; no es conocido en casos de niños.

\section{Métodos de diagnóstico}

El diagnóstico de verrugas ano genitales en niños es hecho generalmente en base a la clínica, pero a la vista de posibles desarrollos medicolegales esto debería ser apoyado por la histología en todos los casos. El diagnóstico diferencial incluye molusco contagiosum, etiquetas 


\section{Enfermedades de transmisión sexual en niños y adolescentes, contagio por el virus del papiloma humano \\ Vol. 2, núm. 3., (2018)}

Bertha Elizabeth Benavides Yánez; Mery Adriana Franco Carrasco; Roberto Jairo Tuesca Armijos; Marcelo Kevin Taiano Espinoza

cutáneas, naevi, neurofibromas y otros tumores benignos. Condylomata lata es raro en estos días, pero siempre debe ser excluido mediante exámenes de laboratorio apropiados para la sífilis.

El examen clínico es pobre para predecir el Tipo de VPH presente. La identificación de este requerirá una técnica virológica que distingue con precisión los genotipos, y esto significa que los tipos de sondas para piel y genitales son usadas. El examen de los padres del niño para evidencia clínica o infección subclínica por VPH puede proporcionar información, pero puede ser difícil de organizar. Finalmente, como cualquier verruga ano genital en un niño puede ser debido al abuso sexual es deseable realizar pruebas de detección para otras enfermedades de transmisión sexual en todos los casos.

\section{Tratamiento y seguimiento}

Las modalidades de tratamiento disponibles para niños con verrugas ano genitales son las mismas que las de adultos: la aplicación de un agente citotóxico o destrucción mecánica de los tumores. Ensayos de tratamiento controlado no se han hecho en niños, entonces la terapia se convierte en una cuestión personal de preferencia basada en la experiencia. Algunos sin embargo, se pueden hacer observaciones generales. La podofilina debe usarse con precaución en niños, debido a las reacciones que implican en la piel circundante, pero la aplicación cuidadosa de una solución al 10\% puede ser útil para lesiones no queratinizadas. Condilomas grandes no deben ser tratados con podofilina porque su potencial tóxico si es absorbido. Si con podofilina la terapia es infructuosa o inapropiada un procedimiento quirúrgico será necesario; se debe usar anestésico local o (más probablemente para niños) un anestésico general. 


\section{Enfermedades de transmisión sexual en niños y adolescentes, contagio por el virus del papiloma humano}

Vol. 2, núm. 3., (2018)

Bertha Elizabeth Benavides Yánez; Mery Adriana Franco Carrasco; Roberto Jairo Tuesca Armijos; Marcelo Kevin Taiano Espinoza

La terapia láser de dióxido de carbono es el tratamiento óptimo, particularmente para condilomas grandes, pero para papilomas pequeños la electro desecación es bastante satisfactoria. Las opiniones se dividen en si o cómo, el VPH en adultos debe ser tratado, y este problema en los niños aún no ha sido dirigido. La vigilancia posterior al tratamiento de los niños con verrugas ano genitales es difícil de decidir en el ausencia de conocimiento de los efectos a largo plazo de la enfermedad.

Si se demuestra el abuso sexual, seguimiento cercano de la familia es obviamente necesario. En todos los casos, sin embargo, la vigilancia durante al menos seis meses después del tratamiento es deseable para detectar lesiones recurrentes. Se ha sugerido que un niño infectado con un tipo viral potencialmente oncogénico (como el VPH 16) debe seguirse con especial cuidado, particularmente después de la pubertad.

\section{Conclusiones}

Existe una necesidad real de cada día obtener más data y conocimientos sobre infecciones ano genitales por VPH en niños. La incomoda pregunta de si las infecciones son causadas por abuso sexual eventualmente se resolverá cuando más casos hayan sido completamente evaluado clínicamente, virológica y socialmente, y entonces pueda ser posible proporcionar pautas para ayudar al clínico a decidir si el niño necesita cuidado y protección.

Prácticamente nada se sabe a largo plazo el desenlace que la infección tendrá en estos niños, Si el virus permanecerá y en algún momento en el futuro infectara a sus parejas cuando se vuelven sexualmente activos? ¿La infección latente por VPH persistirá a pesar de tratamiento 


\section{Enfermedades de transmisión sexual en niños y adolescentes, contagio por el virus del papiloma humano \\ Vol. 2, núm. 3., (2018)}

Bertha Elizabeth Benavides Yánez; Mery Adriana Franco Carrasco; Roberto Jairo Tuesca Armijos; Marcelo Kevin Taiano Espinoza

aparentemente exitoso, y ¿hay alguna posibilidad real de que el intraepitelial vulvar o neoplasia perianal puede desarrollarse en el futuro? Si existe tal posibilidad, ¿es mayor en aquellos infectados con los llamados tipos de "alto riesgo" como el HPV 16? Estos son importantes problemas, y su solución requerirá muchos estudios de plazo de la epidemiología, virología y secuelas de esta enfermedad, que una vez fue rara pero lamentablemente en la actualidad cada dia se está volviendo más común.

\section{Bibliografía}

Goldman, L., \& Clarke, G. (1980). Condyloma Acuminata in Infants and Children. Jama Dermatology.112(9):1329

Marquina, W. (2013). Condiloma Acuminado (Verruga Genital). Revista científica Ciencia Médica. 16(1): 47

Mataix J., Betlloch I., Pasto N., Bañuls J., \& Martínez M., (2008).Verrugas anogenitales: estudio clínico-patológico y virológico. Anales de pediatría. 69(6): 499-595.

Mouesca, J., Indart, M., Stabilito, L. (2012). Verrugas anogenitales y sospecha de abuso sexual infantojuvenil. Archivos argentinos de pediatría. 110(5): 438-444.

Ñíguez, J.C., García L., Pérez, J., Guillén A., Mari, P. (1996). Condilomas acuminados en niños: presentación de un caso, estado actual y protocolo de actuación. Anales Españoles de Pediatría.44: 292-4

Picconi, M. (2013). Detección de virus papiloma humano en la prevención del cáncer cérvicouterino. Medicina (Buenos Aires). 73(6): 585-596

Robinson, A., \& Watkeys J. (1999). Genital warts in children: problems of management. Journal of Clinical Forensic Medicine. 6(3): 151-5

Stumpf, P. (1980). Increasing occurrence of condylomata acuminata in premenarchal children. Obstetric Ginecology. 56(2): 262-4

Zacharisen M., \& Conley S. (2006). Papilomatosis respiratoria recurrente en el niño: simulador de procesos respiratorios comunes. Pediatrics. 62(5). 729-34 